Please send trade news information and illustrations to Terry Mordecai at the BDJ, 64 Wimpole Street, London W1G 8YS. Trade news is supplied as a service to the reader and does not imply endorsement by the BDJ. Normal and prudent research should be exercised before purchase or use of any product mentioned.

\section{Free binoculars}

For the whole of February Alkapharm are offering a free pair of Oxford precision, $8 \times 21$ compact binoculars with every order of $1 \times 1$ litre of Alkacide.

Alkacide is an economical, high performance disinfectant in a cold sterilising solution. Alkapharm claims Alkacide offers many advantages including the fact it is bactericidal, fungicidal, virucidal, and sporicidal.

Alkapharm also claims Alkacide has been formulated so not to give off unpleasant odours, which are often associated with many other sterilising solutions and is therefore ideal for use in the dental surgery. To receive your free binoculars just speak to your Dental Sundries Supplier.

\section{Reader response number 52}

\section{Want to be a Hero?}

JS-Davis is pleased to announce the launch of the Hero Shaper. The Hero Shaper is a new continuous rotation method for root canal preparation with NiTi tapered files

JS-Davis claims the principal advantage is the number of instruments required to treat a canal, either 2, 3 or 4 depending on the degree of difficulty

They also claim the Hero Shaper has an innovative pitch which varies according to the taper, the more tapered an instrument, the longer its pitch.

For more information phone 01707 822520.

\section{Reader response number 53}

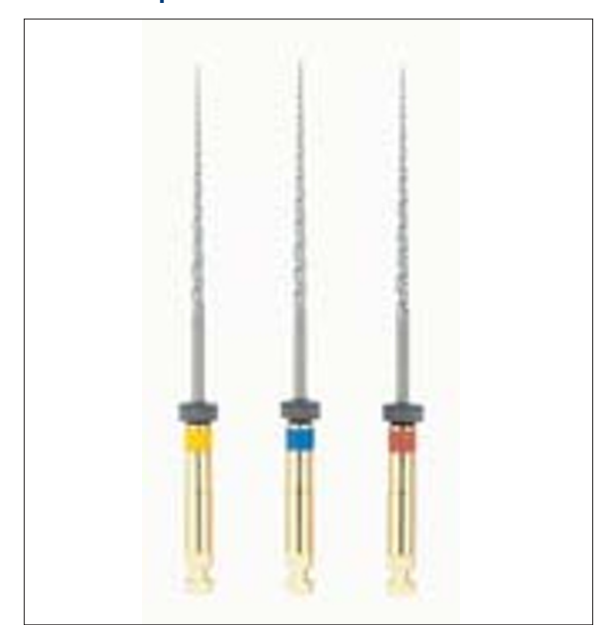

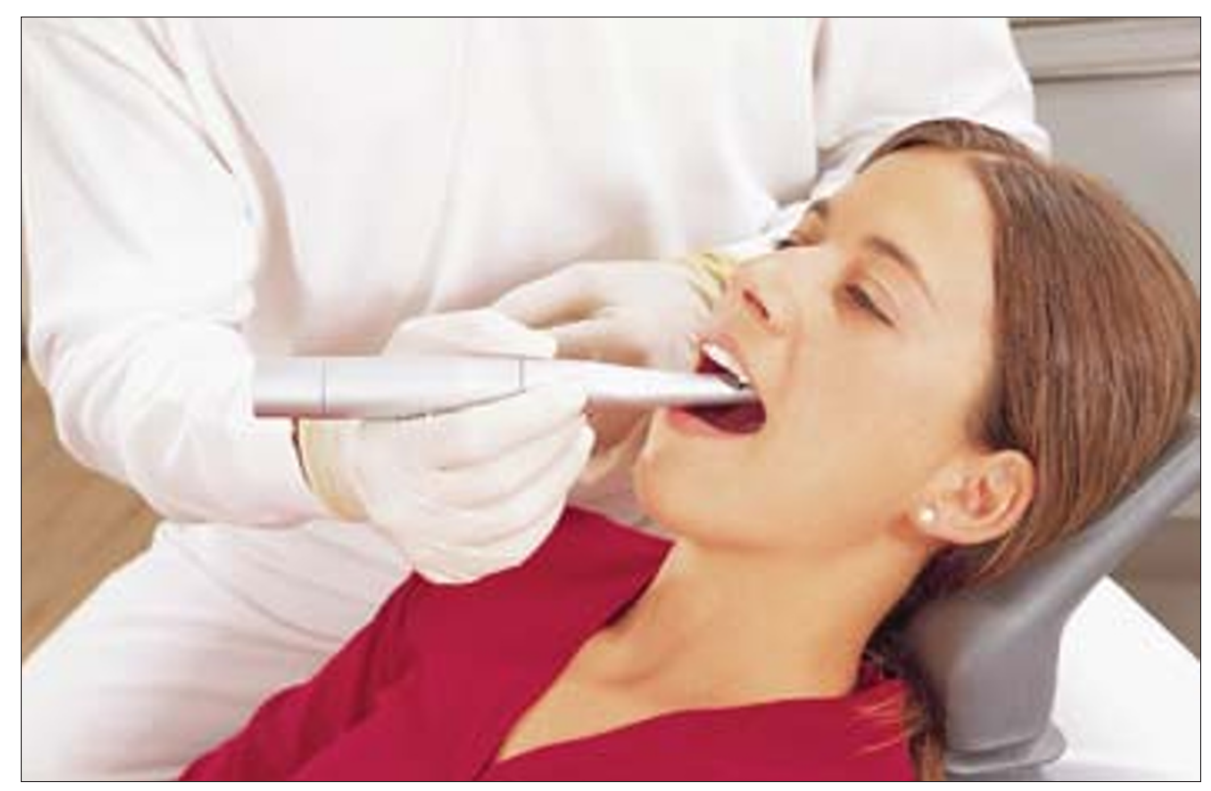

Be mobile with your camera in the surgery

For most people the phrase "I'm on the mobile" is a part of everyday life and for a dentist, 'being on the mobile' could also extend to use of the new Vistacam CL intra-oral camera.

The Vistacam CL is the new wireless optical system from Dürr Dental. The camera is around $100-130 \mathrm{~g}$ in weight. In addition, the camera is versatile enough to enable left to right reversed pictures to be taken with just the touch of a button.

Vistacam CL has all the other advantages of the Vistacam system. Images can be magnified up to 100 times, thus enabling conditions not instantly visible to the human eye (crown margins or secondary caries, for example) to be demonstrated clearly to the patient.

For more information phone 01933-671990.

Reader response number 51

\section{No need to carry toothpaste around anymore}

KYT Ltd is pleased to announce the launch of the FreshctGo all in one toothbrush. The toothbrush looks like any other toothbrush except that when you turn the dial on the brush toothpaste is pushed out of the top of toothbrush through the bristles.

The Fresh\&tGo is designed for immediate and repeated use, cleans teeth and freshens breath at the turn of a dial. KYT Ltd claims it is for people on the go and can be kept in the office, at home, for flights, camping, car trips, or any time your mouth needs a quick rinse.

Fresh\&Go's patented design is equipped with a long brush and compact head, which they also claim reaches into the 'hard to reach' areas while the round-ended soft bristles remove plaque and protect gums. For more information phone 02070258006. Reader response number 54 